\title{
STRATEGI PENGEMBANGAN KAWASAN PELABUHAN PERIKANAN NUSANTARA UNTIA BERBASIS EKOWISATA DI KOTA MAKASSAR
}

\author{
(Strategy For Development of Untia Archipelago Fishing Area Based on \\ Ecotourism In The City of Makassar) \\ Muhammad Ardiansyah ${ }^{1)}$ Danial ${ }^{2)}$, Muhammad Jamal ${ }^{3)}$ \\ 1). Mahasiswa Pasca Sarjana Universitas Muslim Indonesia \\ 2) Dosen Prodi Manajemen Pesisir dan Teknologi Kelautan PPS UMI Makassar \\ 3) Prodi Pemanfaatan Sumberdaya Perikanan FPIK UMI Makassar \\ Korespondensi:muhardiasyahumi@gmail.com
}

Diterima: tanggal 2 Februari 2020; Disetujui 5 Maret 2020

\begin{abstract}
Strategy For Development of Untia Archipelago Fishing Area Based on Ecotourism In The City of Makassar This research was conducted from August 5, 2019 to September 5, 2019, aimed at identifying the potential of ecotourism in the Untia VAT Area mangrove ecosystem, analyzing the suitability of the Untia VAT Area mangrove ecotourism, and determining the strategy of developing mangrove ecotourism in the Untia VAT Area. Data collection was carried out through field surveys and interviews using questionnaires. Data analysis uses area suitability analysis for coastal tourism, mangrove tourism category and SWOT analysis. The results of this study indicate that the potential for ecotourism in the mangrove ecosystem Untia VAT Area is a mangrove area included in the appropriate category to be used as an ecotourism area. The strategy of developing mangrove ecotourism in the Untia PPN Region is to increase human resources (HR), planting abrasion-resistant mangrove species in a sustainable manner, procurement of facilities and infrastructure to support tourism activities, and good cooperation among policy makers.
\end{abstract}

Keywords: Ecotourism, Mangroves, Conformity Analysis and SWOT

\begin{abstract}
ABSTRAK
Strategi pengembangan kawasan pelabuhan perikanan nusantara untia berbasis ekowisata di Kota Makassar. Penelitian ini dilakukan dari bulan 05 Agustus 2019 hingga 05 September 2019, bertujuan untuk mengidentifikasi potensi ekowisata di ekosistem mangrove Kawasan PPN Untia, menganalisis kesesuaian ekowisata mangrove Kawasan PPN Untia, dan menentukan strategi pengembangan ekowisata mangrove pada Kawasan PPN Untia. Pengumpulan data dilakukan melalui survey lapangan dan wawancara dengan menggunakan daftar pertanyaan (kuisioner). Analisis data menggunakan analisis kesesuaian area untuk wisata pantai kategori wisata mangrove dan analisis SWOT. Hasil penelitian ini menunjukkan bahwa potensi ekowisata di ekosistem mangrove Kawasan PPN Untia adalah Kawasan mangrove termasuk dalam kategori sesuai untuk dijadikan kawasan ekowisata. Strategi pengembangan ekowisata mangrove pada Kawasan PPN Untia adalah peningkatan sumber daya manusia (SDM), penanaman jenis mangrove penahan abrasi secara berkelanjutan, pengadaan sarana dan prasarana pendukung kegiatan wisata, dan kerjasama yang baik antar pemangku kebijakan.
\end{abstract}

Kata kunci : Ekowisata, Mangrove, Analisis kesesuaian dan SWOT 


\section{PENDAHULUAN}

Pengembangan

pelabuhan

perikanan merupakan salah satu unsur penting dalam peningkatan infrastruktur perikanan dan bagian dari sistem perikanan tangkap. Adanya pelabuhan perikanan akan mendorong aktivitas perikanan tangkap lebih teratur dan terarah. Pelabuhan perikanan bukan hanya sebatas menyediakan fasilitas untuk aktivitas pendaratan, pengolahan dan pendistribusian hasil tangkapan tetapi juga memberikan pelayanan yang optimal terhadap nelayan sebagai pengguna fasilitas yang tersedia sesuai dengan fungsinya (Atharis 2008).

Mengingat pentingnya kegiatan parawisata untuk mendukung konservasi lingkungan yang sesuai dengan kondisi dimana masyarakat saat ini cukup peka, maka perlunya menginformasikan potensi-potensi Kawasan wisata. Salah satu pelabuhan perikanan nusantara yang ada di Sulawesi selatan adalah pelabuhan perikanan untia merupakan pangkalan pendaratan ikan yang terletak di Kota Makassar yang memiliki potensi ekonomi yang besar untuk di kembangkan khususnya sumberdaya pesisir dan laut yang berbasis ekowisata. Penelitian ini bertujuan untuk mengetahui strategi pengembangan kawasan pelabuhan perikanan nusantara untia berbasis ekowisata di Kota Makassar Sulawesi Selatan.

\section{MATERI DAN METODE}

Penelitian ini telah dilaksanakan pada bulan 05 Agustus 2019 sampai bulan 05 September 2019. Jangka waktu tersebut meliputi persiapan, pengambilan data, analisis data dan terkahir adalah pembahasan hasil penelitian. Penelitian ini akan dilaksanakan di Pelabuhan Perikanan Nusantara Untia Kecamatan Biringkinaya di Kota Makassar Sulawesi Selatan. Data yang dikumpulkan terdiri data primer dan data sekunder, yang dikumpulkan secara langsung di lapangan dan melalui kajian kepustaan lainnya.

Data yang dikumpulkan diolah secara kuantitatif yang meliputi pengolahan data dengan kaidah-kaidah matematik terhadap data angka dan analisis kuantitatif digunakan untuk data ekologi mangrove. Adapun data mengenai kondisi ekologi berdasarkan plot pengamatan diolah untuk 
menganalisis kesesuaian wisata kesesuaian di bawah ini:

mangrove berdasarkan matriks

Tabel 1. Matriks Kesesuaian Area Untuk Wisata Pantai Kategori Wisata Mangrove.

\begin{tabular}{|c|c|c|c|c|c|c|c|c|c|c|}
\hline No & Parameter & Bobot & $\begin{array}{c}\text { Kategori } \\
\text { S1 }\end{array}$ & Skor & $\begin{array}{c}\text { Kategori } \\
\text { S2 }\end{array}$ & Skor & $\begin{array}{c}\text { Kategori } \\
\text { S3 }\end{array}$ & skor & $\begin{array}{c}\text { Kategori } \\
\mathbf{N}\end{array}$ & Skor \\
\hline 1. & $\begin{array}{l}\text { Ketebalan } \\
\text { mangrove } \\
(\mathrm{m})\end{array}$ & 5 & $>500$ & 4 & $\begin{array}{r}>200 \\
500\end{array}$ & 3 & $50-200$ & 2 & $<50$ & 1 \\
\hline 2. & $\begin{array}{l}\text { Kerapatan } \\
\text { mangrove } \\
(100 \mathrm{~m})\end{array}$ & 4 & $>15-25$ & 4 & $>10-15$ & 3 & $5-10$ & 2 & $<5$ & 1 \\
\hline 3. & $\begin{array}{l}\text { Jenis } \\
\text { mangrove }\end{array}$ & 4 & $>5$ & 4 & $3-5$ & 3 & $1-2$ & 2 & 0 & 1 \\
\hline 4. & $\begin{array}{l}\text { Pasang } \\
\text { surut (m) }\end{array}$ & 3 & $0-1$ & 4 & $>1-2$ & 3 & $>2-5$ & 2 & $>5$ & 1 \\
\hline 5. & Obyek biota & 3 & $\begin{array}{l}\text { Ikan, udang, } \\
\text { kepiting, } \\
\text { moluska, } \\
\text { reptil, burung }\end{array}$ & 4 & $\begin{array}{l}\text { Ikan, } \\
\text { udang, } \\
\text { kepiting, } \\
\text { moluska }\end{array}$ & 3 & $\begin{array}{l}\text { Ikan, } \\
\text { moluska }\end{array}$ & 2 & $\begin{array}{l}\text { Salah } \\
\text { satu } \\
\text { biota air }\end{array}$ & 1 \\
\hline 6. & Kekhasan & 1 & Internasional & 4 & Nasional & 3 & Provinsi & 2 & Lokal & 1 \\
\hline
\end{tabular}

Sumber : $\quad$ Dimodifikasi dari Modul Sosialisasi dan Orientasi Penataan Ruang Laut, Pesisir dan PulauPulau Kecil (2002), Yulianda (2007), Bakosurtanal (1995) dan Purbani (1999)

Keterangan :

Nilai maksimum $=80$

Kategori Kesesuaian (\%)

$\mathrm{S} 1=$ Sangat sesuai, dengan nilai $>75-$ $100 \%$

$\mathrm{S} 2=$ Sesuai, dengan nilai $>50-75 \%$

$\mathrm{S} 3=$ Sesuai bersyarat, dengan nilai $>25$

$-50 \%$

$\mathrm{N}=$ Tidak sesuai, dengan nilai $>25 \%$

Selanjutnya berdasarkan

parameter-parameter kesesuaian area dalam tabel di atas, data yang diperoleh di lapangan diolah dengan menggunakan analisis data sebagai berikut :

a. Ketebalan Mangrove/lebar mangrove Nilai yang didapatkan pada pengukuran ketebalan mangrove di lapangan adalah pengukuran lebar mangrove.

b. Kerapatan Jenis

$$
\mathrm{D}=\mathrm{mi} / \mathrm{A}
$$

Keterangan: $\quad \mathrm{Di}=$ Kerapatan jenis (ind $/ \mathrm{m}^{2}$ ) $\mathrm{ni}=$ Jumlah total tegakan jenis $\mathrm{i}$

$\mathrm{A}=$ Luas total area pengambilan contoh

Strategi pengembangan kawasan pelabuhan perikanan nusantara untia berbasis ekowisata di Kota Makassar di gunakan analisis SWOT merupakan tahap analisis lanjutan. Berdasarkan hasil dari analisis deskriptif dan analisis kuantitatif, maka langkah selanjutnya adalah melakukan identifikasi faktorfaktor strategis untuk mengidentifikasi SWOT (Strength, Weakness, Opportunity, Threats) (Rangkuti, 2005 dan Salusu, 1996). 
HASIL DAN PEMBAHASAN

Berdasarkan hasil penelitian dan ketebalan ekosistem mangrove setiap pengukuran dari garis pantai ke arah stasiun seperti pada grafik berikut. darat yang dilakukan di Kawasan PPN

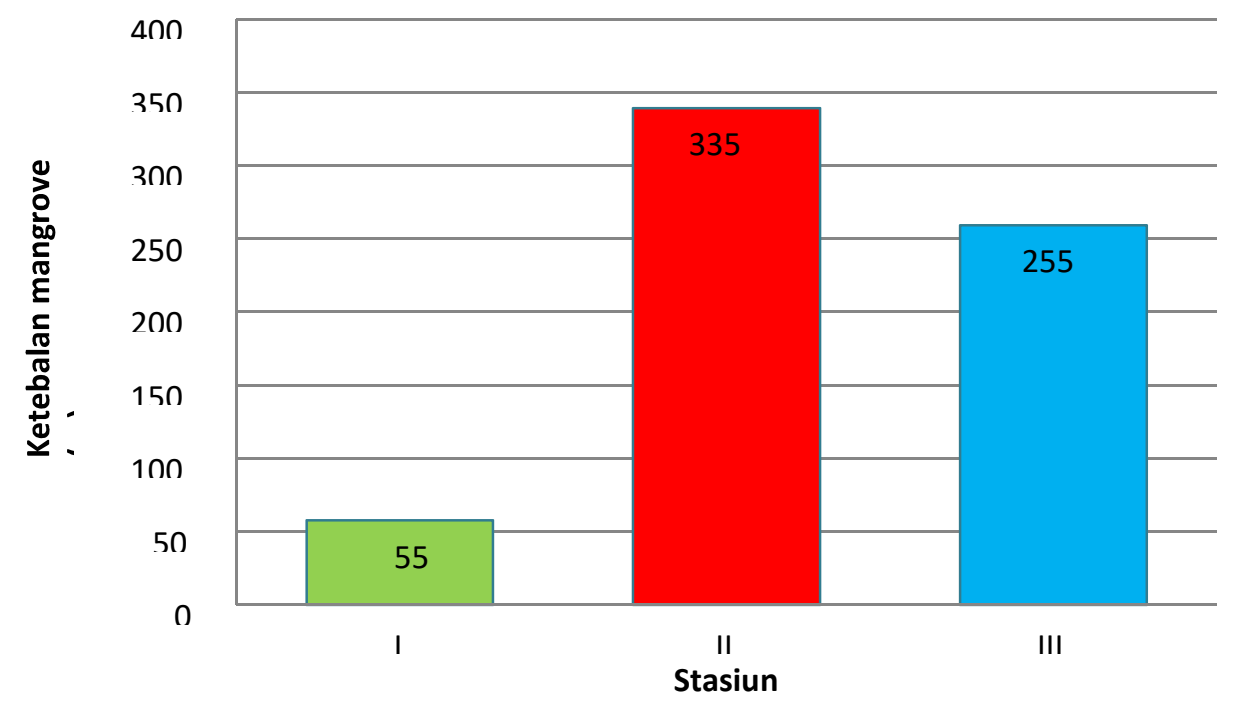

Gambar 1. Diagram ketebalan mangrove per stasiun pada PPN Untia

Berdasarkan gambar di atas Family mangrove yaitu Avicenniaceae terlihat bahwa pada stasiun I memiliki dan Rhizophora apiculata. Spesies yang ketebalan mangrove $55 \mathrm{~m}$, stasiun II di identifikasi antara lain : Avicennia memiliki ketebalan mangrove $335 \mathrm{~m}$ alba, Rhizophora apiculata, dan dan stasiun III memiliki ketebalan Xylocarpus moluccensis dan untuk data mangrove $255 \mathrm{~m}$. Hal ini menjelaskan jenis mangrove yang ditemukan di bahwa ketebalan tertinggi terdapat pada kawasan ekosistem mangrove Kawasan Stasiun II. PPN Untia disajikan dalam Tabel.

Berdasarkan hasil identifikasi Yulianda (2007) yang dilakukan di lapangan dijumpai 2

Tabel 2. Komposisi Jenis Mangrove yang ditemukan di Kawasan Ekosistem PPN Untia.

\begin{tabular}{cclc}
\hline Stasiun & Plot & Species & Pohon \\
\hline I & 1 & Avicennia alba & 2 \\
\cline { 3 - 4 } & & Rhizophora apiculate & 4 \\
\cline { 2 - 3 } & & Xylocarpus moluccensis & 1 \\
\cline { 2 - 3 } & 2 & Avicennia lanata & 2
\end{tabular}




\begin{tabular}{|c|c|c|c|}
\hline & & Rhizophora apiculate & 2 \\
\hline & \multirow[t]{4}{*}{3} & Avicennia alba & 2 \\
\hline & & Rhizophora apiculate & 3 \\
\hline & & Xylocarpus moluccensis & 1 \\
\hline & & & 17 \\
\hline \multirow[t]{7}{*}{ II } & \multirow[t]{2}{*}{4} & Avicennia alba & 4 \\
\hline & & Rhizophora apiculate & 6 \\
\hline & \multirow[t]{2}{*}{5} & Avicennia alba & 5 \\
\hline & & Rhizophora apiculate & 6 \\
\hline & \multirow[t]{3}{*}{6} & Avicennia alba & 4 \\
\hline & & Rhizophora apiculate & 5 \\
\hline & & & 30 \\
\hline \multirow[t]{7}{*}{ III } & \multirow[t]{2}{*}{7} & Avicennia alba & 3 \\
\hline & & Rhizophora apiculate & 4 \\
\hline & \multirow[t]{2}{*}{8} & Avicennia alba & 2 \\
\hline & & Rhizophora apiculate & 5 \\
\hline & \multirow[t]{3}{*}{9} & Avicennia alba & 2 \\
\hline & & Rhizophora apiculate & 4 \\
\hline & & Total & 20 \\
\hline
\end{tabular}

Kerapatan jenis adalah jumlah vegetasi mangrove di kawasan Hutan tegakan jenis I dalam suatu unit area Mangrove Kawasan PPN Untia (Bengen, 2004). Nilai kerapatan jenis disajikan dalam tabel di bawah ini.

Tabel 3. Nilai Kerapatan Jenis Vegetasi Mangrove

\begin{tabular}{|c|c|c|c|c|c|}
\hline Stasiun & Plot & Species & $\begin{array}{c}\text { Jumlah } \\
\text { Pohon (Ni) }\end{array}$ & $\begin{array}{c}\text { Luas } \\
\text { Area } \\
\left(\mathbf{m}^{2}\right)\end{array}$ & $\begin{array}{l}\text { Kerapatan } \\
\text { (Di) }\end{array}$ \\
\hline \multirow[t]{10}{*}{$\mathbf{I}$} & 1 & Avicennia alba & 2 & 100 & 0.02 \\
\hline & & Rhizophora apiculata & 4 & 100 & 0.04 \\
\hline & & Xylocarpus moluccensis & 1 & 100 & 0.01 \\
\hline & 2 & Avicennia lanata & 2 & 100 & 0.02 \\
\hline & & Rhizophora apiculata & 2 & 100 & 0.02 \\
\hline & 3 & Avicennia alba & 2 & 100 & 0.02 \\
\hline & & Rhizophora apiculata & 3 & 100 & 0.03 \\
\hline & & Xylocarpus moluccensis & 1 & 100 & 0.01 \\
\hline & & Total & 17 & 100 & 0.17 \\
\hline & & ta-Rata & & & 0.05 \\
\hline \multirow[t]{7}{*}{ II } & 4 & Avicennia alba & 4 & 100 & 0.04 \\
\hline & & Rhizophora apiculata & 6 & 100 & 0.06 \\
\hline & 5 & Avicennia alba & 5 & 100 & 0.05 \\
\hline & & Rhizophora apiculata & 6 & 100 & 0.06 \\
\hline & 6 & Avicennia alba & 4 & 100 & 0.04 \\
\hline & & Rhizophora apiculata & 5 & 100 & 0.05 \\
\hline & & Total & 30 & 100 & 0.30 \\
\hline
\end{tabular}




\begin{tabular}{|c|c|c|c|c|c|}
\hline \multicolumn{4}{|c|}{ Rata-Rata } & & \multirow{2}{*}{$\begin{array}{l}\mathbf{0 . 1 1} \\
0.03\end{array}$} \\
\hline \multirow[t]{8}{*}{ III } & 7 & Avicennia alba & 3 & 100 & \\
\hline & & Rhizophora apiculata & 4 & 100 & 0.04 \\
\hline & 8 & Avicennia alba & 2 & 100 & 0.02 \\
\hline & & Rhizophora apiculata & 5 & 100 & 0.05 \\
\hline & 9 & Avicennia alba & 2 & 100 & 0.02 \\
\hline & & Rhizophora apiculata & 4 & 100 & 0.04 \\
\hline & & Total & 20 & 100 & 0.20 \\
\hline & & Rata-Rata & & & 0.06 \\
\hline
\end{tabular}

Sumber: diolah berdasarkan hasil pengukuran data dilapangan 2019

Pasang surut adalah proses naik surut di lokasi penelitian dengan turunnya muka laut secara hampir periodik karena gaya tarik benda-benda angkasa, terutama bulan dan matahari menggunakan tongkat penduga pasang surut. Untuk grafik pasang surut disajikan pada Gambar 2 berikut.

(Dahuri, 1996). Pengukuran pasang

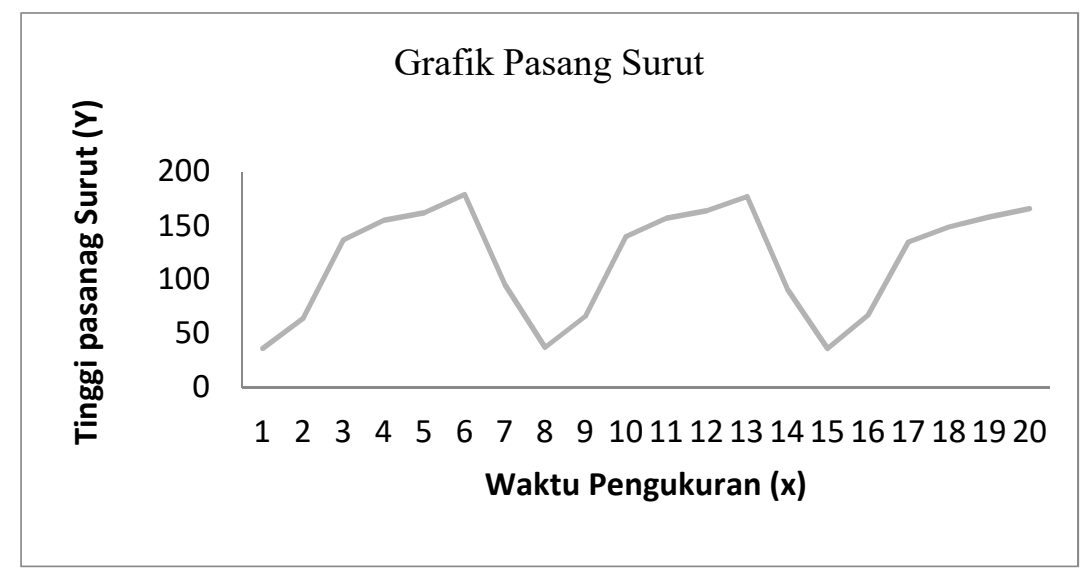

Gambar 2. Pola Pasang Surut Kawasan PPN Untia

Ini menunjukkan bahwa kisaran pasang surut yang diperoleh adalah sebesar $143 \mathrm{~cm}$. Kisaran pasang surut tersebut sudah termasuk kisaran sangat sesuai untuk pemilihan lokasi wisata pantai kategori wisata mangrove untuk parameter pasang surut adalah 0-1 meter dengan mempertimbangkan keamanan serta mempengaruhi distribusi vertikal mangrove. Yulianda (2007) 
Tabel 4. Hasil penilaian kesesuaian lahan untuk ekowisata mangrove

\begin{tabular}{|c|c|c|c|c|c|c|c|}
\hline \multirow{3}{*}{ Parameter } & \multirow{3}{*}{ Bobot } & \multicolumn{6}{|c|}{ Stasiun } \\
\hline & & \multicolumn{2}{|c|}{$\mathbf{I}$} & \multicolumn{2}{|c|}{ II } & \multicolumn{2}{|c|}{ III } \\
\hline & & Skor & Nilai & Skor & Nilai & Skor & Nilai \\
\hline $\begin{array}{l}\text { Ketebalan/Lebar mangrove } \\
(\mathrm{m})\end{array}$ & 5 & 2 & 10 & 3 & 15 & 3 & 15 \\
\hline $\begin{array}{l}\text { Kerapatan mangrove } \\
\left(\text { ind } / 100 \mathrm{~m}^{2}\right)\end{array}$ & 4 & 2 & 8 & 2 & 8 & 2 & 8 \\
\hline Jenis Mangrove & 4 & 3 & 12 & 2 & 8 & 2 & 8 \\
\hline Pasang Surut (m) & 3 & 4 & 12 & 4 & 12 & 4 & 12 \\
\hline Obyek Biota & 3 & 4 & 12 & 4 & 12 & 4 & 12 \\
\hline Kekhasan & 1 & 1 & 1 & 1 & 1 & 1 & 1 \\
\hline Jumlah & & & 55 & & 56 & & 56 \\
\hline Nilai Kesesuaian & & & 69 & & 70 & & 70 \\
\hline Kategori Kesesuaian & & & S2 & & $\mathrm{S} 2$ & & S2 \\
\hline
\end{tabular}

Keterangan : $S 2=$ Sesuai

Berdasarkan tabel diatas dapat disimpulkan bahwa nilai kesesuaian untuk Stasiun I adalah 69\% dengan kategori sesuai, stasiun II adalah 70\% dengan kategori sesuai, dan stasiun III adalah $70 \%$ dengan kategori sesuai (Yulianda, 2007).

Analisis strategi pengembangan ekowisata mangrove di Kawasan PPN
Untia menggunakan Analisis SWOT (Strength, Weakness, Opportunity, and Threats). Tahapan analisis SWOT yang digunakan dalam menganalisis data lebih lanjut yaitu mengumpulkan semua informasi yang mempengaruhi ekosistem pada wilayah kajian, baik secara eksternal maupun secara internal.

Tabel 5. Matriks faktor-faktor strategi internal ekosistem Mangrove

\begin{tabular}{|c|c|c|c|c|c|}
\hline \multirow{2}{*}{ No } & Faktor Strategi Internal & \multirow{2}{*}{ Bobot } & \multirow{2}{*}{ Rating } & \multirow{2}{*}{ Skor } & \multirow{2}{*}{ Akumulasi } \\
\hline & Kekuatan ( Strengths) & & & & \\
\hline 1 & $\begin{array}{l}\text { Keanekaragaman biota yang } \\
\text { tinggi pada daerah mangrove }\end{array}$ & 0.4 & 3 & 1.2 & 0.78 \\
\hline 3 & $\begin{array}{l}\text { Telah ada management } \\
\text { pengelolah wisata pantai }\end{array}$ & 0.2 & 4 & 0.8 & \\
\hline \multirow[t]{2}{*}{4} & $\begin{array}{l}\text { Aksebilitas mudah dijangkau } \\
\text { dari pusat kota }\end{array}$ & 0.1 & 2 & 0.2 & \\
\hline & Kelemahan (Weakness) & & & & \\
\hline 1 & $\begin{array}{l}\text { Kurangnya keanekaragaman } \\
\text { jenis ekosistem mangrove }\end{array}$ & 0.4 & -2 & -0.8 & -0.45 \\
\hline 2 & $\begin{array}{l}\text { Kurangnya sarana dan prasarana } \\
\text { pendukung kegiatan ekowisata }\end{array}$ & 0.3 & -2 & -0.6 & \\
\hline
\end{tabular}




\begin{tabular}{rlccc}
\hline 3 & $\begin{array}{l}\text { Pendidikan rata-rata } \\
\text { masyarakat tergolong rendah }\end{array}$ & 0.1 & -2 & -0.2 \\
\hline 4 & $\begin{array}{l}\text { Konversi lahan menjadi tambak } \\
\text { terus meningkat }\end{array}$ & 0.2 & -1 & -0.2 \\
\hline & 1 & & \\
\hline & Total & & 0.33 \\
\hline
\end{tabular}

Tabel 6. Matriks faktor-faktor strategi internal ekosistem Mangrove

\begin{tabular}{|c|c|c|c|c|c|}
\hline No & $\begin{array}{c}\text { Faktor Strategi Eksternal } \\
\text { Peluang (Opportunities ) }\end{array}$ & Bobot & Rating & Skor & $\underset{\text { si }}{\text { Akumula }}$ \\
\hline 1 & $\begin{array}{l}\text { Daerah mangrove berdekatan } \\
\text { dengan Kawasan PPN Untia }\end{array}$ & 0.4 & 4 & 1.6 & 0.75 \\
\hline 2 & $\begin{array}{l}\text { Dukungan pemerintah terkait } \\
\text { pengembangan kawasan konservasi } \\
\text { tersebut }\end{array}$ & 0.1 & 2 & 0.2 & \\
\hline 3 & $\begin{array}{l}\text { Jumlah sumberdaya masyarakat } \\
\text { yang berpotensi sebagai tenaga } \\
\text { kerja }\end{array}$ & 0.2 & 3 & 0.6 & \\
\hline \multirow[t]{3}{*}{4} & $\begin{array}{l}\text { Banyaknya pengunjung yang } \\
\text { berdatangan ke PPN Untia pada } \\
\text { hari libur }\end{array}$ & 0.3 & 2 & 0.6 & \\
\hline & & 1 & & & \\
\hline & Ancaman ( Threaths ) & & & & \\
\hline 1 & $\begin{array}{l}\text { Terjadinya abrasi pantai di } \\
\text { kawasan konservasi mangrove }\end{array}$ & 0.3 & -3 & -0.9 & -0.65 \\
\hline 2 & Adanya konflik kepentingan & 0.2 & -2 & -0.4 & \\
\hline 3 & $\begin{array}{l}\text { Kurangnya persediaan air bersih di } \\
\text { kawasan mangrove dan kawasan } \\
\text { pantai wisata Mampie }\end{array}$ & 0.1 & -1 & -0.1 & \\
\hline \multirow[t]{3}{*}{4} & $\begin{array}{l}\text { Belum adanya Peraturan Daerah } \\
\text { yang khusus mengatur pengelolaan } \\
\text { Ekosistem Mangrove }\end{array}$ & 0.4 & -3 & -1.2 & \\
\hline & & 1 & & & \\
\hline & Total & & & & 0.10 \\
\hline
\end{tabular}

Matriks strategi eksternal akumulasi sebesar 0,10. Keadaan ini pada Tabel 16 menunjukkan bahwa dapat mengindikasikan bahwa untuk nilai komponen peluang sebesar 0.75 memanfaatkan peluang yang ada dan komponen ancaman sebesar - harusnya mengantisipasi ancaman 0,65. Dari faktor eksternal diperoleh yang mungkin akan terjadi sehingga 
pemanfaatan dapat berjalan sesuai yang diharapkan (Rangkuti, 2005).

Nilai akumulasi dari hasil analisis matriks $\quad$ SWOT, dengan menjumlahkan nilai faktor internal dan eksternal adalah 0,43 menunjukkan bahwa kondisi ekosistem mangrove di kawasan hutan mangrove Kawasan PPN Untia dimanfaatkan sebagai area ekowisata berada pada posisi kuadrant I.

\section{KESIMPULAN}

Potensi ekowisata di ekosistem mangrove Kawasan PPN Untia antara lain adanya berbagai jenis mangrove serta anekaragaman biota di daerah mangrove. Hasil analisis kesesuaian menunjukkan bahwa kawasan mangrove Kawasan PPN Untia termasuk dalam kategori sesuai untuk dijadikan kawasan ekowisata. Strategi pengembangan ekowisata mangrove pada Kawasan Pelabuhan Perikanan Nusantara Untia yaitu : peningkatan sumber daya manusia (SDM) melalui sosialisasi terkait aspek wisata, penanaman jenis mangrove penahan abrasi secara berkelanjutan, pengadaan sarana dan prasarana pendukung kegiatan wisata, dan kerjasama yang baik antar pemangku kebijakan.

\section{SARAN}

Diharapkan adanya penanaman mangrove untuk spesies yang belum ada sehingga keanekaragaman mangrove di Kawasan PPN Untia meningkat serta adanya mangrove penahan abrasi pantai serta memberikan sarana dan prasarana untuk mendukung ekowisata mangrove.

\section{UCAPAN TERIMA KASIH}

Tulisan ini merupakan bagian dari penelitian Tesis dan penulis mengucapkan terima kasih kepada Ketua Prodi Manajemen Pesisir dan Teknologi Kelautan dan Direktur Pasca Sarjana yang telah memberi kesempatan untuk melanjutkan pendidikan di PPS UMI.

\section{DAFTAR PUSTAKA}

Atharis, Y. 2008. Tingkat Kepuasan Nelayan Terhadap Pelayanan Penyediaan Kebutuhan Melaut Di Pelabuhan Perikanan Samudera (PPS) Bungus Sumatera Barat (Skripsi). Bogor : Departeman Pemanfaatan Sumberdaya Perikanan, Fakultas Perikanan dan Ilmu 
Kelautan, Institut Pertanian Yulianda, F. 2007. Ekowisata Bahari

Bogor. 106 hlm.

Bengen, D.G. 2004. Pedoman Teknis

Pengenalan dan Pengelolaan

Ekosistem Mangrove. PKSPLIPB, Bogor sebagai Alternatif Pemanfaatan Sumberdaya Pesisir Berbasis Konservasi. Disampaikan pada Seminar Sains 21 Februari 2007. Departemen M FPIK. IPB. Bogor.

Dahuri. 1996. Pulau Kecil Ditinjau Dari Rangkuti, F. 2005. Analisis SWOT

Kenaikan Permukaan Air Laut Teknik Membedah Kasus

Di Daerah Pesisir Berdasarkan Garis Pantai. Bisnis. PT. Gramedia Pustaka Utama. Jakarta.

Salusu, J. 1996. Pengambilan Keputusan Stratejik Untuk Organisasi Publik dan Organisasi Nonprofit. PT. Gramedia Widiasarana Indonesia. Jakarta. 